\title{
Application of the gamma radiation method in analysing the effect of liquid viscosity and flow variables on slug frequency in high viscosity oil-gas horizontal flow
}

\author{
C. N. Okezue \\ Cranfield University, UK
}

\begin{abstract}
Published experimental observations of high viscosity liquid-gas horizontal flows have indicated that hydrodynamic slug flow is the commonest flow regime encountered over a wide range of flow conditions. Since hydrodynamic slugging generates high pressure fluctuations capable of damaging production pipelines, it is necessary to understand the complex characteristics of high viscosity slug flow regime through the analysis of one of its key parameters namely, slug frequency.

Investigating slug parameters is crucial, especially when existing slug flow models used in the Petroleum Industry are not suitable for predicting the behaviour of high viscosity oil-gas flow. This is because most existing empirical correlations for predicting slug parameters are based on low viscosity liquid-gas flows which have different hydrodynamic features compared to high viscosity liquid-gas flows.

In Cranfield University, an experimental investigation of high viscosity oil-air flow was performed to study the effect of liquid viscosity and flow variables on hydrodynamic slug flow. Experiments were conducted at liquid superficial velocities $\left(\mathrm{V}_{\mathrm{so}}\right)$ and gas superficial velocities $\left(\mathrm{V}_{\mathrm{sg}}\right)$ ranging from $0.06 \mathrm{~m} / \mathrm{s}$ to $2.0 \mathrm{~m} / \mathrm{s}$ and $0.0 \mathrm{~m} / \mathrm{s}$ to $4.0 \mathrm{~m} / \mathrm{s}$ respectively. For each experimental run, a singlebeam gamma densitometer was used to measure slug frequency. The effect of liquid viscosity $(\mu)$ on the measured slug frequency was investigated for the range of $1100 \mathrm{cP}$ to $4000 \mathrm{cP}$. When compared against measured high viscosity slug frequency data, none of the existing empirical correlations used were able to produce accurate predictions. The predicted results tend to diverge from experimental data by several orders of magnitude. Given this context, a new
\end{abstract}


empirical correlation for slug frequency was proposed. The new empirical slug frequency correlation was compared against an independent experimental dataset. The comparison indicated that the new empirical correlation performed better than existing correlations in predicting slug frequency of high viscosity liquid-gas flows.

Keywords: gamma beam densitometer, two-phase flow, hydrodynamic slug flow regime, slug frequency, correlation, multiple-linear regression.

\section{Introduction}

Previous experimental studies on high viscosity liquid-gas horizontal flows have identified hydrodynamic slug flow as the commonest flow regime encountered over a wide range of different flow conditions [1-3]. Unfortunately, mechanistic models currently used for designing and analysing the performance of oil production pipelines and their support systems are not suitable for simulating the characteristics of high viscosity oil-gas systems. This is because the empirical correlations used to close the governing equations of these mechanistic models are based on test data of low viscosity oil-gas flows, which tend to have different hydrodynamic features compared to high viscosity liquid-gas flows.

In this research paper, the effect of high liquid viscosity on slug frequency an important closure relationship for mechanistic slug flow models - was investigated experimentally for the range of $1100 \mathrm{cP}$ to $4000 \mathrm{cP}$. The effects of flow variables on the slug frequency were examined as well. Measured high viscosity slug frequency data was also compared against empirical correlations published in open literature. From these comparisons, it was discerned that there was a need to develop a new slug frequency correlation for high viscosity oil-gas flows, especially for large liquid viscosities of the order of $1000 \mathrm{cP}$ and above.

\section{Experimental system}

\subsection{Layout of test facility}

All experiments were performed in the Three-inch "Cold Heavy Oil Production with Sand" (CHOPS) Test Rig located inside the Multiphase Flow (PASE) Laboratory of the Department of Offshore, Process and Energy Engineering at Cranfield University. As depicted in Figure 1, the test rig includes a horizontal multiphase flow test section and supply systems for compressed air, water, light oil and heavy oil. The horizontal test section consists of transparent Perspex pipes and steel pipes joined together by their end flanges.

Oil-air two-phase flow experiments are not the only tests performed in the CHOPS test rig. As the name of the test rig suggests, high viscosity oil-sandwater three-phase flow experiments are also carried out. Therefore, the test rig contains a slurry mixer for mixing water and sand prior to being pumped into the horizontal flow section containing high viscosity oil. Though there is a facility for supplying oils with viscosities less than $100 \mathrm{cP}$ (i.e. "low-viscosity oils") to the CHOPS test rig, it is rarely used. Oils used in the CHOPS rig are those with 


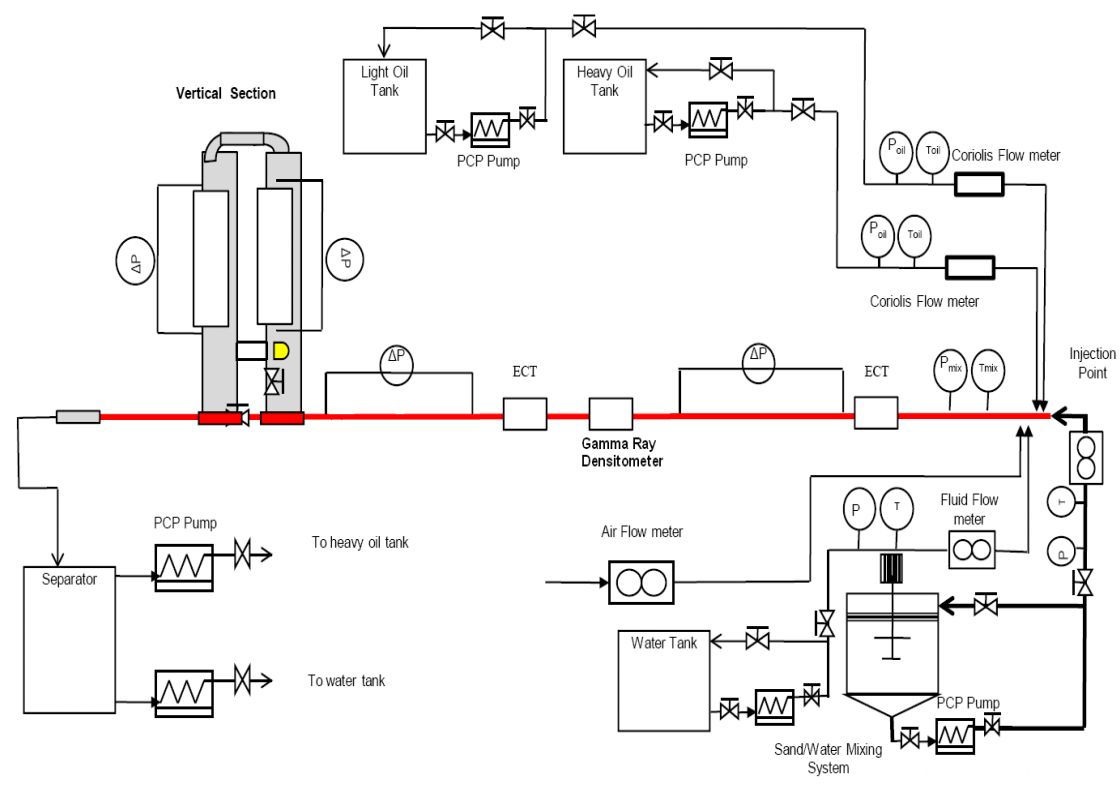

Figure 1: A schematic diagram of the 3-inch CHOPS test rig.

dynamic viscosities in the order of $1000 \mathrm{cP}$ and above (i.e. "high-viscosity oils"). When necessary, the viscosity of the oil phase can be increased by circulating cold refrigerant within the copper coils installed inside the oil tank in order to decrease oil temperature.

Progressive cavity pumps (PCPs) are used to convey water and oil from their respective reservoirs and water-sand slurries from the mixer to the horizontal multiphase flow test section. Compressed air is introduced to the test section with the aid of twin screw compressors. In order to minimize pressure fluctuations, compressed air from the pulsating compressors are passed through a receiver tank which is connected to the horizontal test section of the rig.

The flow rates of the compressed air, oil, water and water-sand slurries are regulated by their respective control valves. Prior to entry into the horizontal test section, the flow rate of air, water and water-sand slurries is measured using various volumetric flow meters. A coriolis meter is used to measure the mass flow rate, density and dynamic viscosity of the oil phase prior to its entry into the test section. The test rig also contains a single beam gamma densitometer and an electrical capacitance tomography (ECT) system for phase fraction measurement.

There is a multi-phase separator present in the CHOPS test rig where the multiphase working fluid from the horizontal flow test section is separated their constituent individual phases according to the magnitude of their density. After separation, water and oil are returned to their reservoirs. Air is allowed to escape into the atmosphere while sand is disposed of. 


\subsection{Instrumentation}

As illustrated in Figure 2, the fixed single-beam gamma densitometer manufactured by Neftemer Ltd consists of a gamma source block and a sodium iodide (NaI) scintillation radiation detector. The gamma source block contains a 5.5 GBq Caesium-137 radioisotope housed within a lead radiation protection shield, which in turn, is encased in stainless steel. The Caesium-137 radioisotope in the Neftemer densitometer is a dual-energy source emitting gamma rays in two broad photon energy levels. The transmitted gamma radiation is the source of the 662-keV high-energy level while scattered gamma radiation is the source of the lower energy level range of $100 \mathrm{keV}-300 \mathrm{keV}$. The sodium iodide (NaI) scintillation radiation detector is used to measure two separate sets of gamma attenuation data for the high and low energy levels at the sampling rate of $250 \mathrm{~Hz}$. For this experimental work, only the measured gamma attenuation data for the high-energy spectrum was used in estimating slug frequency.

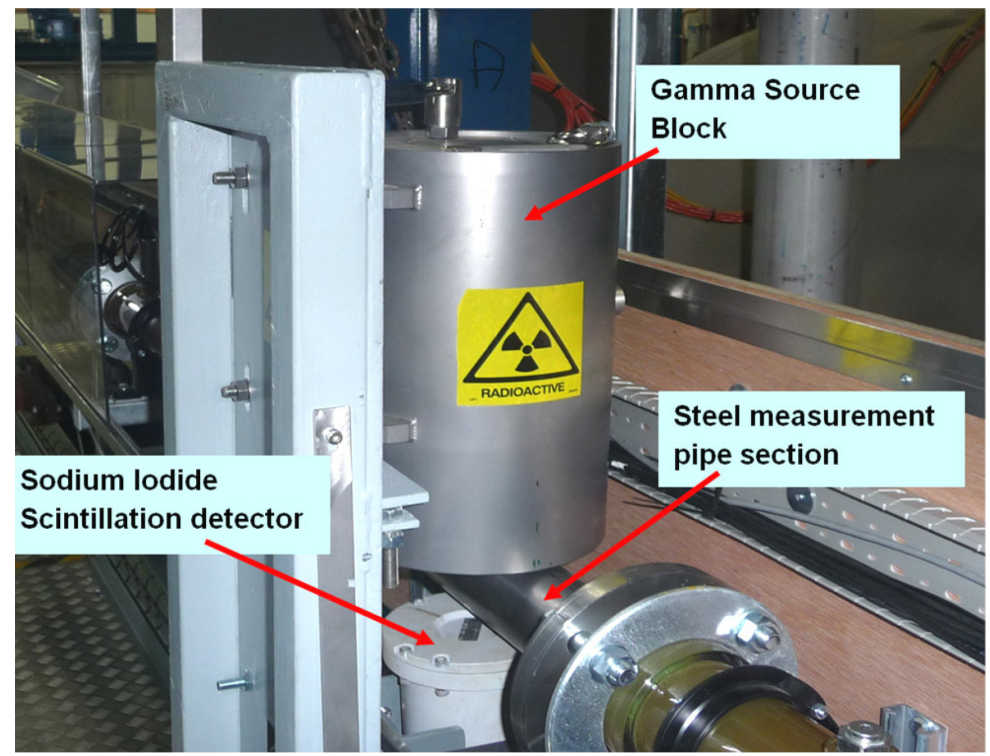

Figure 2: $\quad$ The gamma ray densitometer in the 3-inch CHOPS test rig.

Due to the random nature of gamma photon emissions from the Caesium-137, there is a statistical uncertainty in gamma beam measurements. This uncertainty is inversely proportional to the measurement time. In other words, statistical uncertainty decreases as measurement time is increased. In this present work, the gamma attenuation data was recorded for an average measurement time of 70 seconds per experimental run, giving an average statistical uncertainty of $1.70 \%$. 


\subsection{Test flow conditions}

A series of experiments were performed with the CHOPS rig using the highly viscous CYL-680 oil and compressed air as test fluids. Table 1 summarizes the range of operating conditions covered.

Table 1: $\quad$ Fluid properties and flow conditions of horizontal oil-air flow.

\begin{tabular}{|c|c|c|c|c|}
\hline $\begin{array}{c}\text { Test } \\
\text { Fluid }\end{array}$ & $\begin{array}{c}\text { Density } \\
\left(\mathrm{kg} / \mathrm{m}^{3}\right)\end{array}$ & $\begin{array}{c}\text { Superficial } \\
\text { Velocity }(\mathrm{m} / \mathrm{s})\end{array}$ & Viscosity (cP) & $\begin{array}{c}\text { Surface } \\
\text { Tension } \\
(\mathrm{N} / \mathrm{m})\end{array}$ \\
\hline Air & 1.22 & $\mathbf{V}_{\mathbf{s g}}=0.00-4.00$ & 0.0183 & - \\
\hline Oil & 900.32 & $\mathbf{V}_{\mathbf{s o}}=0.06-0.20$ & $1100-4000$ & 0.0313 \\
\hline
\end{tabular}

\section{Analysis and discussion of experimental results}

\subsection{Effect of flow variables and viscosity on slug frequency}

From the measured gamma attenuation data, liquid holdup data was calculated and then plotted as a function of time to create time-series diagrams. As shown in Figure 3, the peaks in the signal waveforms of the time-series graph are indicative of the passage of liquid slug bodies through the steel measurement pipe section of the gamma densitometer while the troughs indicate the passage of the film region. Slug frequency is estimated by counting the number of peaks and then dividing it by the measurement time.

However, not all liquid holdup time series graphs are as perfect as Figure 3. There are time series diagrams where the peaks are of different heights with some representing the passage of slug bodies and others merely representing travelling waves. In order to isolate travelling waves from slug bodies, a liquid holdup threshold value of 0.7 recommended by Nydal [4] was adopted as shown

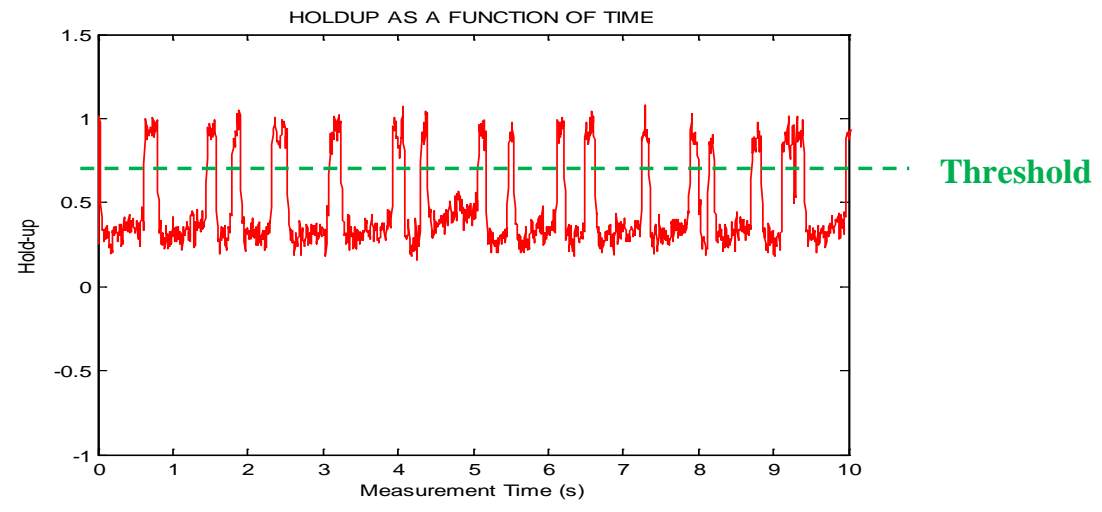

Figure 3: The threshold value in the time-series is used to estimate slug frequency. 


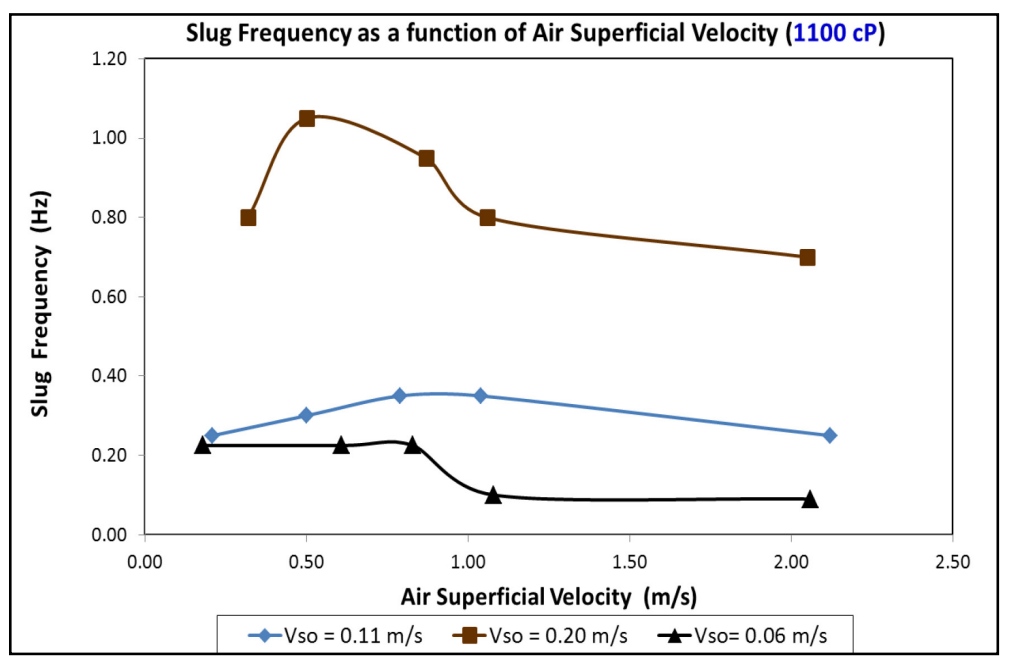

Figure 4: $\quad$ Slug frequency versus air superficial velocity at different liquid velocities for $\mu=1100 \mathrm{cP}$.

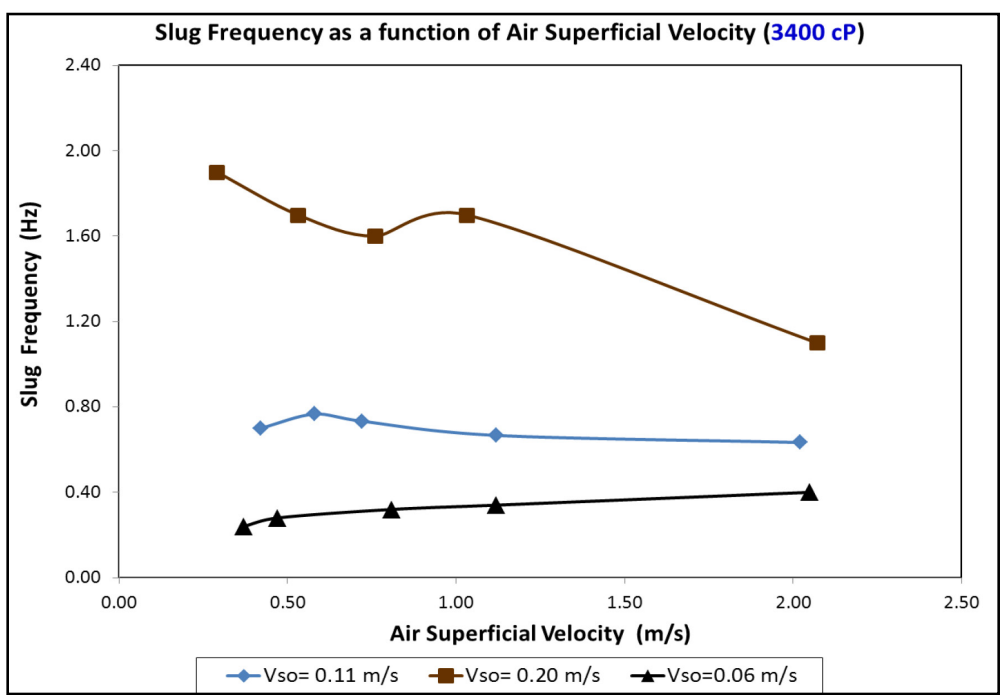

Figure 5: Slug frequency versus air superficial velocity at different liquid velocities for $\mu=3400 \mathrm{cP}$.

in Figure 3. In estimating the slug frequency, only peaks above the liquid holdup threshold value were counted as slug bodies. Peaks below the threshold were considered travelling waves and ignored. Slug frequency was plotted against superficial air velocity for different liquid velocities and 3 oil viscosities namely, $1100 \mathrm{cP}, 3400 \mathrm{cP}$ and $4000 \mathrm{cP}$. The effect of liquid and gas superficial velocities on slug frequency at different viscosities was examined in Figures 4-6. 


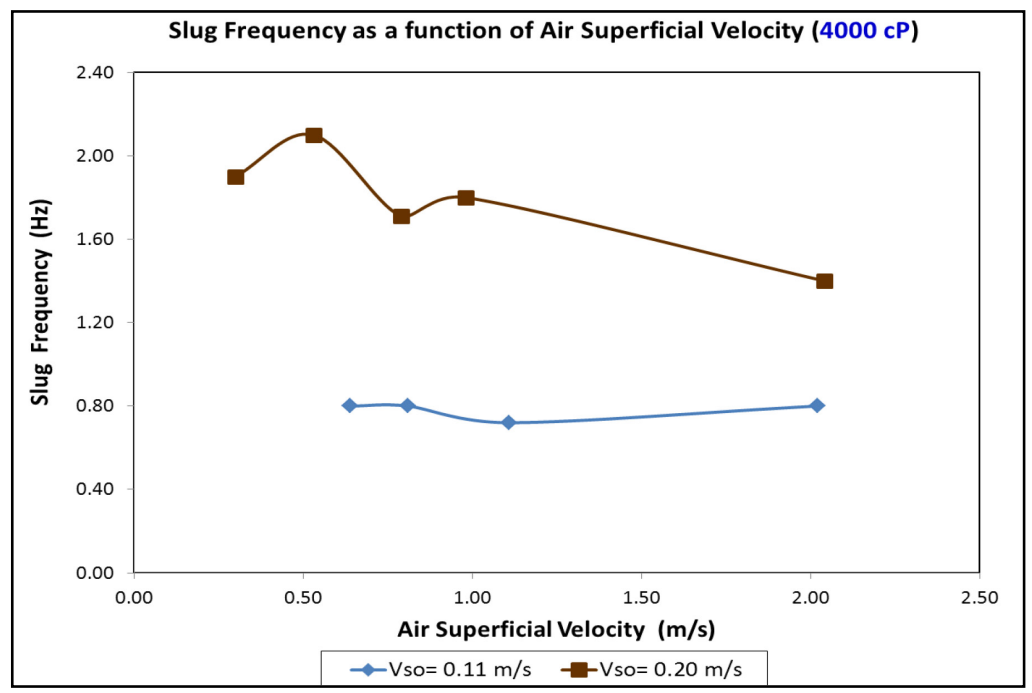

Figure 6: Slug frequency versus air superficial velocity at different liquid velocities for $\mu=4000 \mathrm{cP}$.

From Figures 4-6, it is clear that in general terms, for a particular liquid superficial velocity, the slug frequency increases with increasing superficial gas velocity. The frequency reaches a maximum and then starts declining even though the superficial gas velocity continues increasing. The explanation of this phenomenon has to do with the mechanics of waves at the gas-high viscosity liquid interface. An increase in superficial gas velocity leads to an increase in the in-situ gas velocity, which generates waves at the gas-liquid interface causing slug frequency to rise. However, after a certain superficial gas velocity is reached, the gas phase suppresses liquid hold-up causing the decline of slug frequency thereafter. This is consistent with findings of a number of researchers such as Gokcal et al. [5] for high viscosity liquid-gas flows and Hernandez-Perez [6] for low viscosity liquid-gas flows.

More importantly, increasing superficial liquid velocity has the effect of causing slug frequency to increase as well as illustrated in Figures 4-6. The obvious explanation is that increasing liquid superficial velocity induces an increase in the liquid level within the horizontal pipe section. In other words, increasing the liquid superficial velocity reduces the amount of time needed to fill the pipe section up to the liquid level required for the formation of the next slug body in accordance with Kelvin-Helmholtz stability phenomenon.

To examine the effect of liquid viscosity variation on slug frequency for a given set of liquid superficial velocities, Figures 7-9 were plotted. 


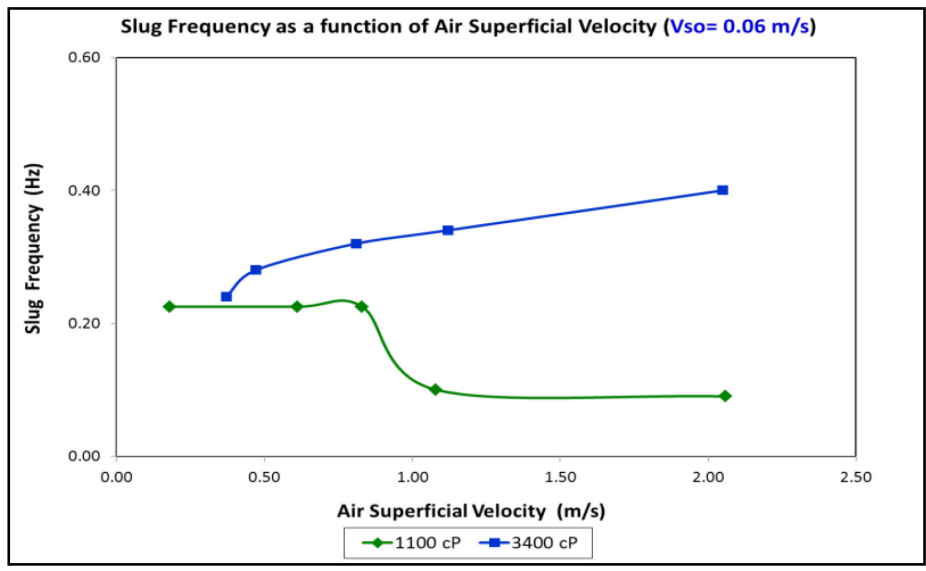

Figure 7: $\quad$ Slug frequency versus air superficial velocity at different liquid viscosities for $\mathrm{V}_{\mathrm{so}}=0.06 \mathrm{~m} / \mathrm{s}$.

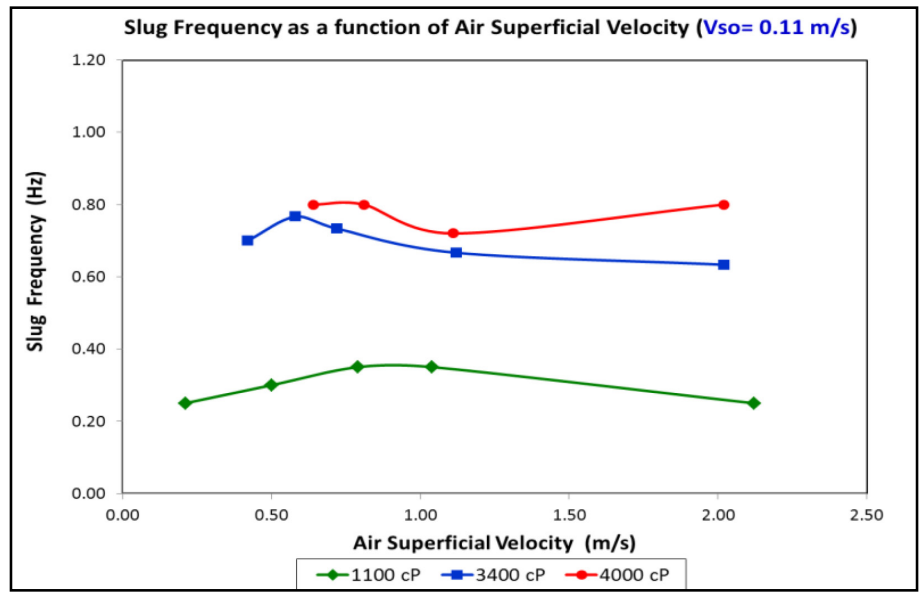

Figure 8: Slug frequency versus air superficial velocity at different liquid viscosities for $\mathrm{V}_{\mathrm{so}}=0.11 \mathrm{~m} / \mathrm{s}$.

From Figures 7-9, it is clear that slug frequency increases as liquid viscosity is increased. The explanation for this viscosity effect is as follows: the liquid level in the pipe section increases with increasing liquid viscosity. An increase in liquid level increases the probability for the occurrence of the critical liquid height required for the formation of slug bodies in accordance with the KelvinHelmholtz stability phenomenon. The findings reported above are consistent with experimental observations made by Colmenares et al. [1] and Gokcal et al. [5]. It is also clear from Figures 7-9 that slug frequency is dependent on liquid viscosity. However, many existing empirical correlations for predicting slug frequency fail to account for the effect of liquid viscosity. 


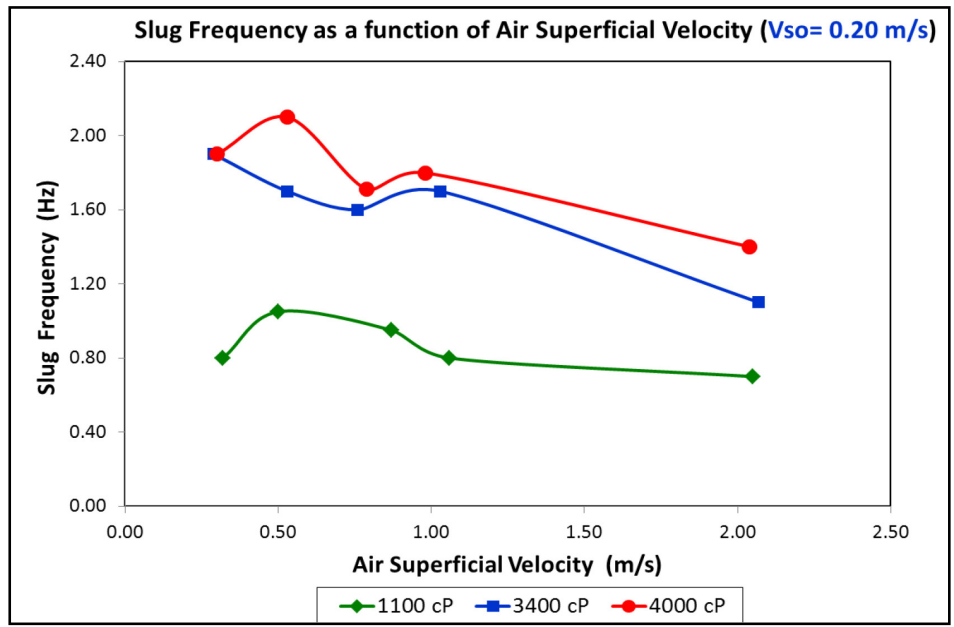

Figure 9: $\quad$ Slug frequency versus air superficial velocity at different liquid viscosities for $\mathrm{V}_{\mathrm{so}}=0.20 \mathrm{~m} / \mathrm{s}$.

\subsection{Comparison of experimental slug frequency against existing empirical correlations}

Experimental slug frequency was compared to predicted results of different empirical correlations for liquid viscosities of $1100 \mathrm{cP}, 3400 \mathrm{cP}$ and $4000 \mathrm{cP}$ for the superficial liquid velocity of $0.11 \mathrm{~m} / \mathrm{s}$.

From Figures 10-12, it is obvious that none of the slug frequency correlations were able to produce predictions of reasonable accuracy. The predicted results

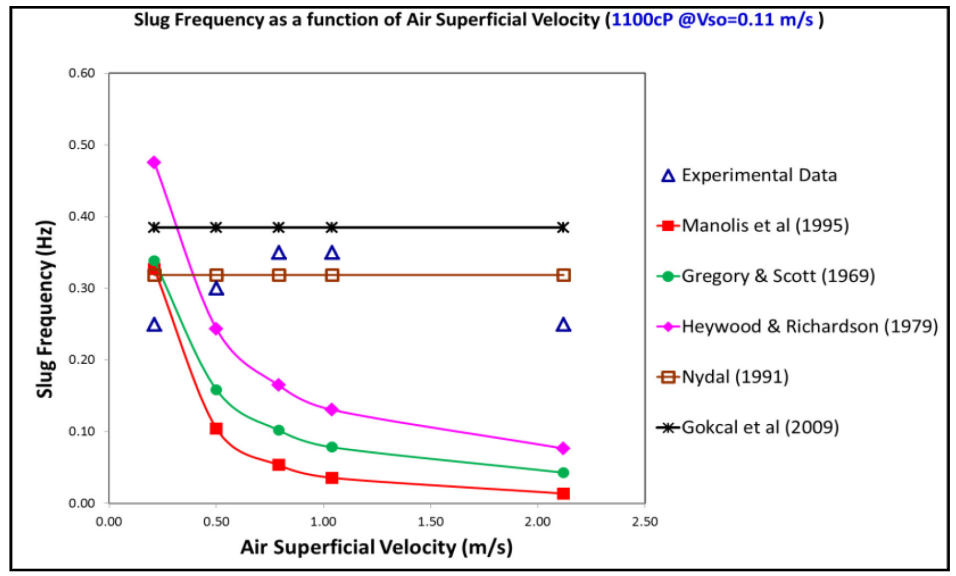

Figure 10: Experimental slug frequency versus empirical correlations for $\mathrm{V}_{\mathrm{so}}=0.11 \mathrm{~m} / \mathrm{s}$ and $\mu=1100 \mathrm{cP}$. 
tend to diverge from experimental data by several orders of magnitude. Similar trends were noticed for comparisons between experimental and predicted slug frequencies performed for other superficial liquid velocities. Slug frequency correlations developed by Gregory and Scott [7], Heywood and Richardson [8], Nydal [4] and Manolis et al. [9] perform poorly because they all fail to account for the effect of liquid viscosity. These empirical correlations are based on horizontal slug flow tests with gas and low viscosity liquids (typically water or kerosene) where the effects of liquid viscosity are minor.

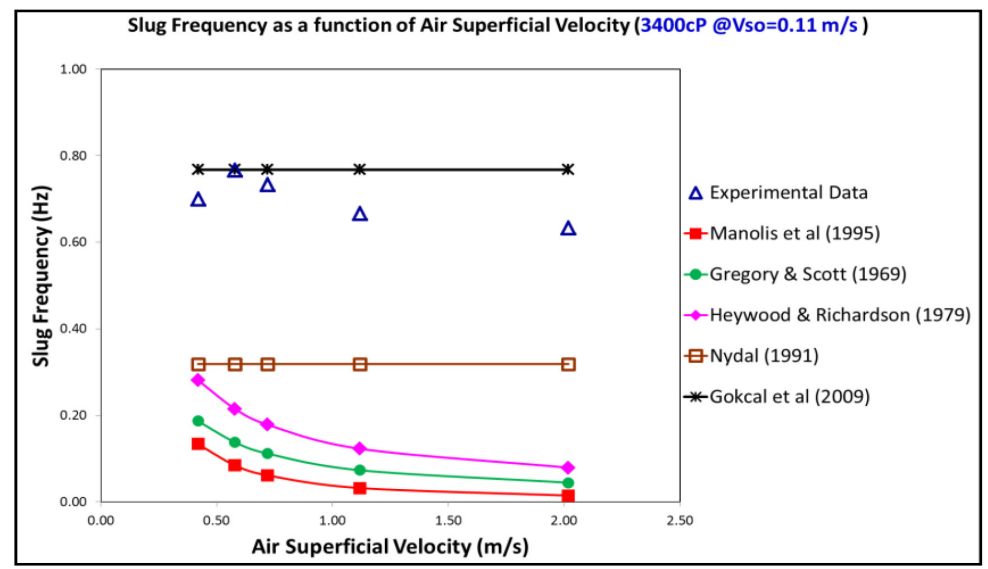

Figure 11: Experimental slug frequency versus empirical correlations for $\mathrm{V}_{\mathrm{so}}=0.11 \mathrm{~m} / \mathrm{s}$ and $\mu=3400 \mathrm{cP}$.

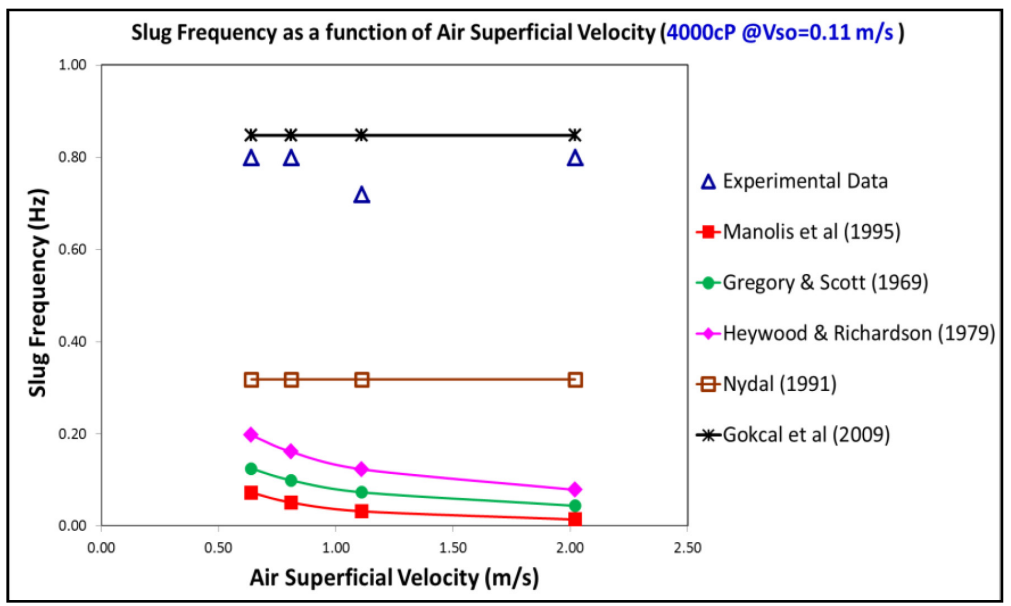

Figure 12: Experimental slug frequency versus empirical correlations for $\mathrm{V}_{\mathrm{so}}=$ $0.11 \mathrm{~m} / \mathrm{s}$ and $\mu=4000 \mathrm{cP}$. 
The slug frequency correlation developed by Gokcal et al. [5] is the only one that took explicit account of the effects of high liquid viscosity by balancing viscous and gravitational forces acting on hydrodynamic slug flow. Therefore, compared to the other correlations, predictions made with the Gokcal et al. [5] correlation was relatively closer to the experimental data. Unfortunately, as seen in Figures 10-12, predictions performed with the Gokcal et al. [5] correlation are insensitive to variation in the gas superficial velocity. In other words, this correlation is unlikely to perform well in conditions where gas flow rate is high enough to exercise strong influence over slug frequency. More importantly, the Gokcal et al. [5] correlation is based on high viscosity liquid-gas flow tests with liquid viscosity limited to the range of $181 \mathrm{cP}-587 \mathrm{cP}$.

To quantify the discrepancies between experimental data and predicted results in graphs above, table 2 was produced. Three statistical parameters namely Average Percentage Relative Error (APE), Average Absolute Percentage Relative Error (AAPE) and Standard Deviation of Relative Error - were used to analyze the performance of the empirical correlations.

As seen in table 2, the correlations either grossly overestimate or underestimate the slug frequency. In the case of the Shea et al. [10] correlation, the error exceeded $100 \%$, meaning that the predictive results generated from it were far away from the reality observed in the experiments. Generally, the error

Table 2: $\quad$ Evaluation of slug frequency correlations using statistics.

\begin{tabular}{|c|c|c|c|c|}
\hline \multirow[t]{2}{*}{ Correlation } & $\begin{array}{c}\text { Liquid } \\
\text { Viscosity }\end{array}$ & APE & AAPE & $\begin{array}{c}\text { Standard } \\
\text { Deviation }\end{array}$ \\
\hline & {$[\mathrm{cP}]$} & [\%] & [\%] & {$[\%]$} \\
\hline \multirow{3}{*}{ Manolis et al. [9] } & 1100 & -70.48 & 74.57 & 35.97 \\
\hline & 3400 & -89.76 & 89.76 & 7.99 \\
\hline & 4000 & -92.53 & 92.53 & 6.09 \\
\hline \multirow{3}{*}{$\begin{array}{l}\text { Gregory and } \\
\text { Scott [7] }\end{array}$} & 1100 & -58.52 & 63.60 & 35.55 \\
\hline & 3400 & -82.90 & 82.90 & 11.34 \\
\hline & 4000 & -88.44 & 88.44 & 4.63 \\
\hline \multirow{3}{*}{$\begin{array}{l}\text { Heywood and } \\
\text { Richardson [8] }\end{array}$} & 1100 & -36.29 & 56.69 & 49.39 \\
\hline & 3400 & -72.79 & 72.79 & 17.71 \\
\hline & 4000 & -81.88 & 81.88 & 6.20 \\
\hline \multirow{3}{*}{ Nydal [4] } & 1100 & 8.40 & 49.37 & 68.67 \\
\hline & 3400 & -44.59 & 48.78 & 34.01 \\
\hline & 4000 & -62.87 & 64.10 & 26.45 \\
\hline \multirow{3}{*}{ Shea et al. [10] } & 1100 & 169.08 & 169.08 & 112.34 \\
\hline & 3400 & 35.54 & 45.14 & 46.55 \\
\hline & 4000 & 16.50 & 36.11 & 67.40 \\
\hline \multirow{3}{*}{ Gokcal et al. [5] } & 1100 & 12.20 & 26.89 & 38.52 \\
\hline & 3400 & 12.33 & 22.35 & 27.05 \\
\hline & 4000 & 15.86 & 29.80 & 60.29 \\
\hline
\end{tabular}


seems to increase as liquid viscosity varies from $1100 \mathrm{cP}$ to $4000 \mathrm{cP}$. This trend strongly indicates that there is a need for new empirical correlations that can account properly for effect of extremely high liquid viscosity on oil-gas flows.

\section{Development of a new slug frequency correlation for high viscosity liquid-gas flows}

Using Buckingham Pi Theorem, 4 dimensionless groups were generated from physical quantities that are known to influence slug frequency namely, liquid viscosity $(\mu)$, gas density $\left(\rho_{\mathrm{G}}\right)$, liquid density $\left(\rho_{\mathrm{L}}\right)$, mixture velocity $\left(\mathrm{V}_{\mathrm{M}}\right)$, superficial liquid velocity $\left(\mathrm{V}_{\mathrm{SL}}\right)$ and pipe diameter $(\mathrm{D})$.

The dimensionless groups obtained are: Strouhal Number; Liquid volume fraction; Mixture Froude Number and Mixture Reynolds Number as shown in

$$
\left(\frac{\text { Freq } \times D}{V_{M}}\right)=\Psi\left(\frac{V_{S L}}{V_{M}} ; \operatorname{Fr}_{M} ; \operatorname{Re}_{M}\right)
$$

Using multiple linear regression analysis, a new slug frequency correlation was developed on the basis of high viscosity oil-gas test dataset for three liquid viscosities (1100 cP, $3400 \mathrm{cP}$ and $4000 \mathrm{cP})$ and oil superficial velocities of $0.06 \mathrm{~m} / \mathrm{s}, 0.11 \mathrm{~m} / \mathrm{s}$ and $0.20 \mathrm{~m} / \mathrm{s}$. The new correlation for slug frequency (Freq) yielded by the regression analysis is

$$
\text { Freq }=\left(\frac{3.6102}{D}\right)\left(\frac{V_{S L}^{1.299}}{V_{M}^{0.299}}\right)\left(\frac{\mathrm{Fr}_{\mathrm{M}}^{0.497}}{\operatorname{Re}_{\mathrm{M}}^{0.531}}\right)
$$

\subsection{Statistical evaluation of the proposed empirical correlation}

A plethora of statistical parameters were used to evaluate the overall reliability of the newly developed empirical correlation as shown in table 3 below:

Table 3: Overall Statistical Evaluation of the slug frequency correlation.

\begin{tabular}{|c|c|c|c|c|c|}
\hline Model dF & Error $\mathrm{dF}$ & $\mathrm{SSE}$ & $\mathrm{MSE}$ & $\mathrm{R}^{2}$ & Adjusted $^{2}$ \\
\hline 3 & 40 & 5.002 & 0.125 & 0.893 & 0.885 \\
\hline
\end{tabular}

In table 3, the degree of freedom for the empirical model (i.e. "model dF") is three, reflecting the fact that three independent variables - Mixture Reynolds Number $\left(\operatorname{Re}_{\mathrm{M}}\right)$; Mixture Froude Number $\left(\mathrm{Fr}_{\mathrm{M}}\right)$ and Liquid volume fraction $\left(\mathrm{V}_{\mathrm{SL}} / \mathrm{V}_{\mathrm{M}}\right)$ - were used to develop the new slug frequency correlation. The Sum of Squares Error (SSE) quantifies the discrepancy between the actual values of the dependent variable and the predictions performed with the empirical slug 
frequency model. The mean squared error (MSE) quantifies the degree of the scatter of the data around the idealistic straight line in the graph.

The " $\mathrm{R}$ " " value (also called "coefficient of determination") is a measure of the fraction of the variation in the dependent variable (i.e. Strouhal Number) that can be predicted by the independent variables - " $\mathrm{Re}_{\mathrm{M}}$ "; " $\mathrm{Fr}_{\mathrm{M}}$ " and "V $\mathrm{V}_{\mathrm{SL}} / \mathrm{V}_{\mathrm{M}}$ ".

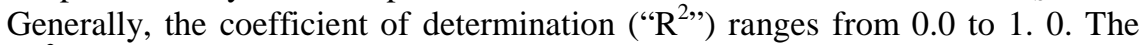
" $\mathrm{R}$ " value is 0.0 when none of the variation in the dependent variable can be predicted by the independent variables - meaning that there is no linear relationship between the dependent and independent variables. Conversely, " $\mathrm{R}^{2 \text { ", }}$ is 1.0 , when all the variations in the dependent variable can be predicted exactly

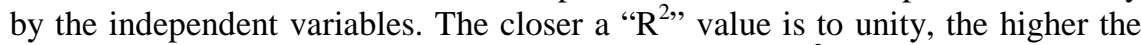

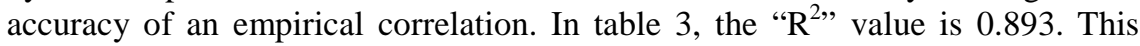
means that $89.3 \%$ of the variation in the dimensionless slug frequency can be explained by the independent variables. In other words, the proposed slug frequency correlation is a good regression model.

Without accounting for the number of independent variables present, the " $\mathrm{R}^{2 \text { ", }}$ value quantifies how well an empirical model fits test data in a regression graph. Since empirical models with several independent variables can "twist" and

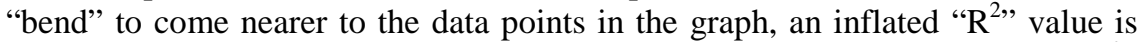

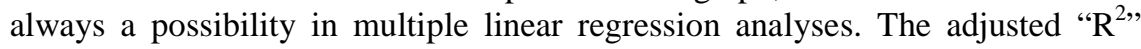
value tackles this problem by accounting for the number of independent variables present an empirical model. The closer an adjusted " $\mathrm{R}$ ") value is to unity, the higher the accuracy of the empirical model. In table 3 , the adjusted " $\mathrm{R}$ ") value for the proposed slug frequency correlation is 0.885 .

\subsection{Comparison of proposed and existing slug frequency correlations against high viscosity experimental data}

As part of the process of model validation, the newly developed empirical correlation was compared against independent high viscosity oil-gas data. Existing correlations in literature were also tested against the independent data in order to compare their performance to the newly developed correlation.

The independent dataset was obtained from the 3-inch CHOPS test rig for liquid viscosity of $2500 \mathrm{cP}$ at $\mathrm{V}_{\mathrm{so}}=0.11 \mathrm{~m} / \mathrm{s}$ and was not included in the process of developing the new empirical correlation. As stated earlier, the empirical correlation was developed solely from the combined oil-gas datasets for $1100 \mathrm{cP}$, $3400 \mathrm{cP}$ and $4000 \mathrm{cP}$.

From table 4, it is clear that the correlations either overestimate or underestimate the slug frequency. Nevertheless, the newly developed slug frequency correlation outperformed the published correlations when judged by their APE and AAE values. In other words, with a relative error of $15.55 \%$, the predictions of the newly developed slug frequency correlation are closest to experimental data in terms of accuracy. However, the standard deviation of the newly developed slug frequency correlation was quite high in comparison to the other existing correlations. 
Table 4: $\quad$ Performance evaluation of proposed and existing correlations using statistics.

\begin{tabular}{|c|c|c|c|c|}
\hline \multirow{2}{*}{ Correlation } & $\begin{array}{c}\text { Liquid } \\
\text { Viscosity }\end{array}$ & APE & AAE & $\begin{array}{c}\text { Standard } \\
\text { Deviation }\end{array}$ \\
\cline { 2 - 5 }$\left[\begin{array}{c}\text { [cP] } \\
{[\%]}\end{array}\right.$ & {$[\mathrm{Hz}]$} & 16.66 \\
\hline Manolis et al. [9] & 2500 & -82.49 & 0.370 & 18.19 \\
\hline $\begin{array}{c}\text { Gregory and } \\
\text { Scott [7] }\end{array}$ & 2500 & -73.33 & -0.408 & 25.56 \\
\hline $\begin{array}{c}\text { Heywood and } \\
\text { Richardson [8] }\end{array}$ & 2500 & -58.76 & -0.335 & 16.22 \\
\hline Nydal [4] & 2500 & -37.81 & -0.221 & 45.83 \\
\hline Shea et al. [10] & 2500 & 75.70 & 0.360 & 32.38 \\
\hline $\begin{array}{c}\text { Gokcal } \text { et al. [5] } \\
\text { Newly Developed } \\
\text { Correlation }\end{array}$ & 2500 & 24.14 & 0.096 & 38.54 \\
\hline
\end{tabular}

\section{Conclusion}

The effect of viscosity and flow variables on slug frequency was investigated experimentally. It was found that increasing liquid viscosity and oil superficial velocity caused a corresponding increase in slug frequency. Existing slug frequency correlations published in open literature were tested against experimental data. None of them were able to produce predictions of reasonable accuracy. Generally, the errors in the predictions increased as liquid viscosity varies from $1100 \mathrm{cP}$ to $4000 \mathrm{cP}$. This trend strongly indicated a need for a new slug frequency correlation that can account properly for effect of extremely high liquid viscosity on oil-gas flows. On the basis of dimensional analysis and multiple linear regression analysis, a new empirical slug frequency correlation was developed. This newly developed slug frequency correlation was compared against an independent experimental dataset. The comparison indicated that the new empirical correlation performed better than existing correlations in terms of predicting slug frequency for high viscosity liquid-gas flows. This means that the new correlation can significantly improve the accuracy of mechanistic models for analysing hydrodynamic slugging in horizontal high viscosity liquid-gas production pipelines.

\section{Acknowledgements}

The author will like to acknowledge The Process Systems Engineering Research Group at Cranfield University, UK for the provision of laboratory facilities. The author thanks BP Plc. for building the 3-inch CHOPS test rig and Neftemer Ltd for providing the gamma densitometer used in all the oil-gas experiments. Additionally, the author thanks all his research colleagues who helped in getting the test rig to run smoothly during experiments. 


\section{References}

[1] Colmenares, J., Ortega, P., Padrino, J. and Trallero, J.L., 2001. "Slug flow model for the prediction of pressure drop for high viscosity oils in a horizontal pipeline”. SPE International Thermal Operations and Heavy Oil Symposium, Margarita Island, Venezuela.

[2] Gokcal, B., Wang, Q., Zhang, H.Q and Sarica, C., 2006. "Effects of high oil viscosity on oil/gas flow behaviour in horizontal pipes". SPE Annual Technical Conference and Exhibition, San Antonio, Texas, USA.

[3] Matsubara, H. and Naito, K., 2011. "Effect of liquid viscosity on flow patterns of gas-liquid two-phase flow in a horizontal pipe". International Journal of Multiphase Flow, 37(10), pp. 1277-1281.

[4] Nydal, O.J., 1991. "An experimental investigation of slug flow”. $\mathrm{PhD}$ Thesis, University of Oslo, Norway.

[5] Gokcal, B., Al-Sarkhi, A.S., Sarica, C. and Al-Safran, E.M., 2009. "Prediction of Slug Frequency for High-viscosity oils in horizontal pipes". SPE European Formation Damage Conference, New Orleans, Louisiana, USA.

[6] Hernandez-Perez, V., 2007, Gas-liquid two-phase flow in inclined pipes. $\mathrm{PhD}$ Thesis, University of Nottingham, United Kingdom.

[7] Gregory, G.A. and Scott, D.S., 1969. "Correlation of liquid slug velocity and frequency in horizontal co-current gas-liquid slug flow". AIChE Journal, 15 (6), pp. 933-935.

[8] Heywood, N.I. and Richardson, J.F., 1979. "Slug flow of air-water mixtures in a horizontal pipe: determination of liquid hold-up by gamma-ray absorption”. Chemical Engineering Science, 34, pp. 17-30.

[9] Manolis, I., Meendes-Tatis, M. and Hewitt, G., 1995. "The effect of pressure on slug frequency in two-phase horizontal flow". 2nd International conference on Multiphase flow, Kyoto, Japan.

[10] Shea, R.H., Eidesmoen, H., Nordsveen, M., Rasmussen, J., Xu, Z.G. and Nossen, J., 2004. "Slug frequency prediction method comparisons". Proceedings of the 4th North American Conference on Multiphase Technology, pp. 227-237. 